\title{
Repercussões do trabalho de conclusão de curso no processo de formação inicial de professores da educação profissional
}

\author{
Repercussions of course conclusion in the initial training process \\ of teachers of professional education
}

\section{Resumo}

Este ensaio discorre sobre a presença do Trabalho de Conclusão de Curso (TCC) no processo de formação inicial de professores da Educação Profissional (EP) e as repercussões no processo formativo, a partir da sistematização, cuja base é a revisão bibliográfica e de apontamentos, ao longo da atuação como professores de Metodologia Científica, Pesquisa em Educação e Trabalho de Conclusão de Curso na última década. Tal modo de abordagem se assenta numa perspectiva dialética, seguindo os movimentos e contradições próprios dos espaços educativos e, portanto, sociais. Como organização, o trabalho encontra-se estruturado de modo que apresenta as singularidades, o significado e as repercussões do TCC na formação inicial de professores de EP. Esses pontos, apresentados de forma interligada e interdependente, indicam que o processo de desenvolvimento do TCC é uma

\footnotetext{
${ }^{1}$ Possui graduação em Pedagogia pela Fundação de Ensino do Desenvolvimento do Oeste (1986), especialização em Supervisão Escolar pela Fundação de Ensino do Desenvolvimento do Oeste (1988), Mestrado em Educação pela Universidade de Passo Fundo - UPF (2000) e Doutorado em Educação pela Pontifícia Universidade Católica do Rio Grande do Sul PUCRS (2011). Atualmente é Professor de Ensino Básico, Técnico e Tecnológico da área de Pedagogia do Instituto Federal de Educação, Ciência e Tecnologia do Rio Grande do Sul (IFRS) - Campus Sertão. É professor permanente do Programa de Pós-Graduação em Educação Profissional e Tecnológica (ProfEPT). Tem experiência na área de Educação, com ênfase em didática e organização pedagógica do ensino, atuando principalmente nos seguintes temas: formação de professores, práticas pedagógicas, educação profissional, educação superior e educação do campo. E-mail: josimar.vieira@sertao.ifrs.edu.br.

2 Possui Graduação em Estudos Sociais pela Fundação de Ensino do Desenvolvimento do Oeste (1983), Graduação em Pedagogia pela Fundação de Ensino do Desenvolvimento do Oeste (1984), Graduação em História pela Fundação Educacional do Oeste Catarinense (1987), Curso de Especialização em Supervisão Escolar (1988), Mestrado em Educação pela Universidade de Passo Fundo (1999), Graduação em Direito pela Universidade Comunitária da Região de Chapecó (2007), Curso de Especialização em Direito Processual Civil pela Universidade Comunitária da Região de Chapecó (2009), , Mestrado em Direito pela Universidade Federal de Santa Catarina (2011) e doutorado em Educação nas Ciências (2017) pela UNIJUI. É professora titular do Instituto Federal do Rio Grande do Sul - IFRS Câmpus Sertão, atuando nos seguintes temas: educação profissional - formação de professores - politicas da educação.E-mail: marilandi.vieira@sertao.ifrs.edu.br.
} 
atividade que permite vivenciar experiências de ensino com pesquisa que são consideradas oportunidades para desenvolver saberes fundamentais e necessários à formação de professores da EP.

Palavras-chave: Educação Profissional. Formação de professores. Trabalho de Conclusão de Curso.

\begin{abstract}
This essay discusses the presence of the Course Completion Work (TCC) in the process of initial formation of teachers of Vocational Education (EP) and the repercussions in the formative process, based on the systematization, whose basis is the bibliographic review and notes, along with acting as teachers of Scientific Methodology, Research in Education and Course Completion Work in the last decade. This way of approach is based on a dialectical perspective, following the movements and contradictions proper to educational spaces and, therefore, social. As an organization, the work is structured in a way that presents the singularities, meaning and repercussions of $C B T$ in the initial training of PE teachers. These points, presented in an interconnected and interdependent way, indicate that the development process of CBT is an activity that allows to experience experiences of teaching with research that are considered opportunities to develop fundamental knowledge and necessary for the formation of teachers of PE.
\end{abstract}

Key words: Professional Education. Teacher training. Completion of course work.

\title{
Introdução
}

Uma análise sobre o Trabalho de Conclusão de Curso (TCC) exige desenredar, antes, de qual TCC se está discorrendo, tendo em vista as inúmeras perspectivas de se entender o desenvolvimento desta prática. Entendemos o TCC sob duas perspectivas dentro da formação inicial de professores. Na primeira, é um processo que abarca todas as experiências vivenciadas pelo estudante durante a realização do seu processo formativo, com o objetivo de promover o seu envolvimento com a pesquisa e, consequentemente, sua formação científica, incluindo programas de treinamento, desenvolvimento de estudos sobre a metodologia científica (dentro de um componente curricular ou não), visitas programadas a instituições de ensino e pesquisa, etc. Na segunda, o TCC é definido como o 
desenvolvimento de um projeto de pesquisa elaborado e realizado sob orientação de um professor da instituição de ensino, executado com ou sem bolsa para os estudantes (MASSI; QUEIROZ, 2015).

De uma forma ou de outra, trata-se de uma atividade importante no contexto acadêmico porque tem como propósito a fecundação e proliferação do conhecimento, utilizando a pesquisa para atingir este objetivo, se apresentando, assim, como um instrumento de aprendizado e agente de fomento à interação entre o estudante, o professor, a instituição de ensino e a comunidade.

No que diz respeito ao processo de formação inicial de professores de Educação Profissional (EP), a inserção do estudante em projetos de pesquisa se torna um instrumento relevante para aprimorar qualidades desejadas em um profissional de nivel superior, bem como para estimular e iniciar a formação direcionada para a pesquisa. Para desenvolver um projeto de pesquisa é necessário buscar o conhecimento existente na área, formular o problema e o modo de enfrentá-lo, coletar e analisar dados, e tirar conclusões. Aprende-se a lidar com o desconhecido e a encontrar novos conhecimentos.

Diante dessas ponderações surgiu o interesse pela presente temática que busca compreender as repercussões do TCC no processo de formação inicial de professores da EP, tendo como referência nossa trajetória como professores dos componentes curriculares Metodologia Científica (MC), Pesquisa em Educação (PE) e Trabalho de Conclusão de Curso (TCC) do Curso de Licenciatura em Ciências Agrícolas (LICA) do Instituto Federal de Educação, Ciência e Tecnologia do Rio Grande do Sul (IFRS) - Campus Sertão, assim como a condição de professores-orientadores de TCCs produzidos neste curso. Sendo professores de um curso de licenciatura tivemos a oportunidade de acompanhar o processo de desenvolvimento do TCC, se envolvendo com grupos de pesquisa, interagindo com colegas professores e estudantes, participando de eventos, sendo membros de bancas de defesa e socialização dos trabalhos gerados e articulando 
conhecimentos produzidos por professores/pesquisadores com a realidade das instituições de ensino.

Em se tratando da formação inicial de professores para a EP, o desenvolvimento do TCC parece ser ainda mais complexo e desafiador. Isso se deve ao fato de que esta modalidade de ensino está integrada aos diferentes niveis e modalidades de educação e às dimensões do trabalho, da ciência e da tecnologia e tem como função social a educação tecnológica, entendida de forma ampla e universal. Para se ter uma ideia da abrangência da EPT, vale destacar o art. 39, § $2^{\circ}$ da LDB - Lei $\mathrm{n}^{\circ}$ 9.394, de 20 de dezembro de 1996, onde consta que a EPT "Abrangerá os seguintes cursos: I - de formação inicial e continuada ou qualificação profissional; II - de educação profissional técnica de nível médio; III - de educação profissional tecnológica de graduação e pós-graduação" (BRASIL, 1996, p. 17).

A análise que decorre neste ensaio se concentra na formação de professores para atuar em cursos de formação inicial e continuada ou qualificação profissional e na educação profissional técnica de nivel médio. Considerando que esta pretensão é abrangente, a produção deste ensaio se concentrou na compreensão das seguintes questões: que singularidades são possiveis de serem apontadas no TCC que é desenvolvido no processo de formação inicial de professores da EP? Qual a acepção do TCC na formação inicial de professores da EP? E quais as repercussões do TCC no processo de formação inicial de professores da EP?

Destarte, na busca de compreender os efeitos do TCC na formação inicial de professores da EP, este ensaio está organizado em três partes, conforme segue: inicia compreendendo singularidades do TCC que é desenvolvido no processo de formação inicial de professores da EP; na segunda parte aponta a acepção do TCC na formação inicial de professores da EP; na sequência (terceiro momento) são esboçadas as repercussões do TCC no processo de formação inicial de professores da EP e por fim, apresenta as considerações finais deste estudo. 


\section{Desenvolvimento e singularidades do tcc no processo formativo inicial de professores da EP}

Em se tratando de curso de formação inicial de professores da EP, o TCC tem importância pois possui como propósito a fecundação e proliferação do conhecimento, utilizando a pesquisa para atingir este objetivo, se apresentando, assim, como um instrumento de aprendizado e agente de fomento à interação entre o estudante, a instituição de ensino formadora e a comunidade.

Para o desenvolvimento do TCC, torna-se necessário que o estudante esteja adquirindo no seu curso, saberes pedagógicos e epistemológicos vistos como centrais para a sua realização, que segue um rigor técnico-científico. É imprescindivel um certo amadurecimento intelectual para a escolha do tema de pesquisa, que deve atender à sua área de formação e ter relevância acadêmica, trazendo benefícios não só para ele, mas, sobretudo, para a sociedade em geral.

Esse aspecto assume posição relevante já que a investigação é o caminho pelo qual encontramos respostas para inquietações do cotidiano que desafiam a prática educativa. O movimento de valorização da pesquisa na formação de professores tem sua origem nos anos de 1960, na Inglaterra, nos currículos formulados pelas escolas de inovação, e aqui no Brasil tem encontrado ressonância nas proposições de pesquisadores que têm se dedicado a estudo sobre o professor e a pesquisa na educação, a exemplo de André (2004) e de Lüdke et al. (2009).

A inclusão da pesquisa por meio do TCC e a valorização da prática na formação dos professores estão expressas nos documentos legais que estabelecem as diretrizes e bases da educação nacional. A Lei de Diretrizes e Bases da Educação Nacional (Lei n. 9.394/96) define no seu Artigo 61 os fundamentos metodológicos que regularão a formação de profissionais para atuarem nos diferentes níveis e modalidades de ensino, enfatizando a "[...] associação entre teorias e práticas, inclusive mediante a capacitação em serviços [...]" (BRASIL, 1996, p. 19).

Em se tratando do TCC no curso LICA envolvido neste ensaio, 
constatamos que estão contemplados no seu projeto pedagógico, componentes curriculares voltados para esta finalidade. Mais especificamente, na matriz curricular encontram-se o componente curricular Metodologia Científica (MC) no primeiro semestre, Pesquisa em Educação (PE) no sexto semestre e no sétimo e oitavo semestres os componentes Trabalho de Conclusão de Curso (TCC) I e II respectivamente. Em TCC I e II, cada estudante ou dupla de estudantes devem desenvolver uma pesquisa, elaborando e desenvolvendo o projeto, produzindo o relatório e comunicando os resultados em eventos programados para esta finalidade.

O TCC no curso de licenciatura envolvido neste ensaio está coerente com a Resolução $n^{\circ} 2$, de $1^{\circ}$ de julho de 2015 que definiu as Diretrizes Curriculares Nacionais para a formação inicial em nivel superior (cursos de licenciatura, cursos de formação pedagógica para graduados e cursos de segunda licenciatura) e para a formação continuada (BRASIL, 2015). De acordo do o artigo $7^{\circ}$, espera-se que o egresso, entre outras habilidades, seja apto a

\footnotetext{
XI - realizar pesquisas que proporcionem conhecimento sobre os estudantes e sua realidade sociocultural, sobre processos de ensinar e de aprender, em diferentes meios ambiental-ecológicos, sobre propostas curriculares e sobre organização do trabalho educativo e práticas pedagógicas, entre outros;

XII - utilizar instrumentos de pesquisa adequados para a construção de conhecimentos pedagógicos e científicos, objetivando a reflexão sobre a própria prática e a discussão e disseminação desses conhecimentos.
}

No curso LICA do IFRS - Campus Sertão, uma das principais preocupações que merece destaque diz respeito ao que se entende por pesquisa. Em artigo de Gatti, esse tema é manifestado de forma condensada, conforme segue:

A palavra pesquisa pode denotar desde a simples busca de informações, localização de textos, eventos, fatos, dados, 
locais, até o uso de sofisticação metodológica e uso de teoria de ponta para abrir caminhos novos no conhecimento existente, e mesmo criação de novos métodos de investigação e estruturas de abordagem do real. [...] Em ambos os casos é preciso sair do nivel do recolhimento de informações superficiais ou de senso comum, sair da "opinionatria", e buscar, com método, uma compreensão que ultrapasse nosso entendimento imediato, elaborando um conhecimento que desvende processos obscuros, subjacentes, um conhecimento que lance luz sobre fenômenos, sobre uma questão, segundo algum referencial (GATTI, 2006, p. 26).

Considerando esta contribuição de Gatti e os objetivos do TCC I e II que consta no projeto pedagógico do curso LICA, na qual apresenta preocupação com o exercício da produção científica por meio da pesquisa do espaço escolar, percebendo e interpretando a concretude dos problemas educacionais, constatamos que esse processo de produção acadêmica representa experiência de produção de pesquisa, sendo considerada oportunidade para desenvolver saberes fundamentais e necessários à formação de professor da EP, principalmente a capacidade crítico-reflexiva do trabalho escolar e da escola como instituição social. Para Lüdke; Cruz (2005), a possivel articulação entre ensino e pesquisa no trabalho do professor é algo que há algum tempo tem merecido atenção de pesquisadores. Desde a década de 90 o tema "professor pesquisador" tem ganhado espaço de discussão acadêmica com a difusão do trabalho de D. Schön e a de saber docente.

As discussões e pesquisas em torno dessa e de outras temáticas a ela relacionadas têm se tornado cada vez mais intensa. Dentre várias preocupações apontadas na literatura acadêmica, alguns aspectos críticos estão inquietando particularmente o processo de formação inicial de professores. Tomando o caso que está sendo analisado neste ensaio, constatamos que os TCCs desenvolvidos pelos estudantes do curso LICA do IFRS - Campus Sertão se aproxima dessas preocupações. Nossa experiência 
como professores deste processo revelou que a realização de pesquisas significa um importante momento na formação inicial de professores da EP, proporcionando o desenvolvimento de habilidades necessárias e a compreensão crítica do contexto educacional. Considerando nossa trajetória como professores formadores de professores, podemos afirmar que com o desenvolvimento de pesquisas, a formação inicial de professores se alterou significativamente, se constituindo numa experiência onde aprendem o processo de produção de conhecimento e ao mesmo tempo adquirem habilidades para atuar como professores.

Para a análise dessas considerações são necessários outros entendimentos o que nos remete para isso instaurar outras interlocuções a partir da literatura acadêmica. Nesta direção, Demo (1997) apresenta a abordagem educacional, o educar pela pesquisa, que tem como base o questionamento reconstrutivo. No questionamento reconstrutivo, a construção do conhecimento se dá através de uma reformulação de teorias e conhecimentos existentes. O questionamento reconstrutivo encaminha um novo tipo de construtivismo, em que, retira-se a ênfase da construção e direciona-a para uma reconstrução do conhecimento.

Moraes; Ramos; Galiazzi (2002) caracterizam o processo do educar pela pesquisa como um movimento dialético composto por três princípios: questionamento, construção de argumentos e comunicação. O primeiro princípio inicia-se através do questionamento de teorias e conteúdos existentes. Neste princípio são apontadas falhas e limitações nos objetos de estudo e procura-se identificar novos caminhos para ampliar os seus entendimentos. Contudo, estes novos caminhos devem possuir uma base teórica sólida. Assim encaminha-se o segundo princípio, onde ocorre a construção de argumentos para solidificar as novas ideias. Após os argumentos terem sido construídos e organizados eles devem ser comunicados. Isto constitui o terceiro princípio, que tem como objetivo colocar os argumentos produzidos para a análise e avaliação de um grupo maior. A partir desta análise podem surgir novas críticas o que pode desencadear um novo movimento no ciclo, ou seja, um novo 
questionamento, uma nova construção de argumentos e uma nova comunicação. Assim o educar pela pesquisa pode ser visto como um movimento interativo e recursivo.

Tanto as contribuições de Demo como de Moraes; Ramos; Galiazzi apontam outras significações possíveis para a pesquisa na formação inicial de professores da EP. É possível perceber que o "espírito de investigação" só passará a fazer parte do dia a dia do futuro professor da EP no momento em que, no decorrer do processo de formação, venha acontecer uma proposta de TCC que realize uma triangulação entre os princípios científico, formativo e educativo da pesquisa. Nessa triangulação, respeitadas as especificidades de cada um dos princípios, será possivel criar-se um espaço de formação inicial de professores da EP em que a pesquisa em seu princípio científico defina, ampare e alimente os aspectos formativos e educativos e que estes, pelo seu sentido pedagógico, estimulem o pensamento dos estudantes, mantendo-os em constante estado de aprender a aprender e saber pensar para que possam intervir no mundo de forma responsável, alimentando a pesquisa como princípio científico e sendo alimentados por ela na prática docente.

\section{Acepção do TCC na formação inicial de professores da EP}

Entendemos o TCC como uma ação intencional e metodologicamente estruturado na busca de uma resposta para uma pergunta previamente elaborada. Compreendemos que para produzir pesquisa é necessário ser criativo, reinventar a história e os fazeres humanos sob um olhar particular. Trata-se de uma atividade coletiva, cuja função primordial é atribuir sentidos ao cotidiano, revendo e significando identidades e histórias. Neste processo, o diálogo assume função preponderante, ou seja, é preciso garantir não só o relato, mas a reflexão sobre as ideias relatadas. Utilizamos a ideia de diálogo na perspectiva de Paulo Freire enquanto estratégia de elaboração e explicitação de concepções reveladora da relação entre os sujeitos e a realidade, com base na qual se dá o processo de conscientização, emancipação e superação de desigualdades (FREIRE, 1986). No entanto, ao se pensar especificamente na situação dos professores, sobretudo em escolas 
públicas, percebe-se que a conscientização nem sempre é condição de emancipação. Estes professores muitas vezes, estão conscientes de sua situação, mas se sentem incapacitados para propor alterações e sentirem-se menos assujeitados. Sua condição de profissional está incluída nos discursos que o circundam, representada em falas que não são suas. Simplesmente dialogar sobre estas falas não representa modificá-las, é preciso agir em relação a elas. Assim, a pesquisa surge como possibilidade de refletir e agir sobre discursos impostos, implementando uma significação por meio da linguagem.

Diante dessas considerações, o significado do TCC na formação inicial de professores da EP é inquestionável, tornando-se atividade significativa e determinante. Essa compreensão de formação exige troca, diálogo e interação entre os sujeitos da ação pedagógica, integrando o estudante como sujeito da construção do conhecimento. Esse procedimento redireciona o paradigma vigente que se concentra mais nas condições de ensino do que na aprendizagem. Essa concepção de ensino/aprendizagem baseia-se em atitudes analíticas, reflexivas, questionadoras e problematizadoras, em que o ponto de partida é as próprias observações que, por sua vez, levam a indagar sobre o conhecimento e a realidade.

No entanto, a inquietação e a preocupação vivenciada na prática de um curso de licenciatura, que permeia este estudo, se traduzem em alguns pontos polêmicos, dentre os quais é possivel destacar: o tipo de pesquisa realizada, as concepções de pesquisa circulantes, os aportes teóricos que têm balizado tal fazer acadêmico, a formação para a pesquisa proporcionada na formação inicial nas diferentes áreas, as condições objetivas que assistem estudantes e professores-orientadores, a relação instituição de ensino superior - escola básica, enquanto nascedouro dessas pesquisas, dentre outros.

Como professores, podemos declarar que essas pré-ocupações estão presentes no dia a dia do processo de desenvolvimento do TCC na formação inicial de professores da EP. Temos experimentado grandes desafios em relação a essa atividade, percebendo que os estudantes se encontram 
desmotivados e até mesmo impotentes na construção satisfatória do TCC. Esta constatação nos exige criar meios de mobilizar o estudante para o desenvolvimento de seu trabalho de pesquisa, fazendo com que ele perceba o seu trabalho como algo mais do que o comprimento formal de um (ou mais) componente curricular, tarefa essa que mesmo obrigatória deve ter o seu comprometimento.

No caso deste curso de licenciatura envolvido neste ensaio, são comuns manifestações dos estudantes expressando sensação de frustração relacionada principalmente com dificuldades enfrentadas nas orientações e a pressão por busca de uma produção de qualidade. É comum estudantes que demonstram cansaço e, às vezes, desânimo diante deste processo. Constatamos que logo no início da realização do TCC, estudantes resistem aos primeiros procedimentos, principalmente na definição do tema e problema de pesquisa. Nos projetos que envolvem o uso de pessoas, o envio dos dados para o Comitê de Ética em Pesquisa representa mais um obstáculo que é necessário ser vencido. São necessárias muitas idas e vindas até poder ter oportunidade para encontrar um tema relevante relacionado com a EP. Muitas vezes envolve um local que acolha a investigação o que repercute posteriormente nas coletas de dados quando o projeto requerer. A produção do relatório exige muito acompanhamento do professor-orientador, assim como a realização da banca de socialização do trabalho desenvolvido. A preparação para a realização da banca normalmente é um processo que preocupa o estudante sendo que após a sua realização, a sensação que se tem é que a experiência ajudou na sua formação e na compreensão da síntese da investigação realizada.

Tais pontos sinalizam que o processo de desenvolvimento da pesquisa na formação inicial de professores da EP é complexo e representa um problema que a instituição de ensino superior precisa enfrentar com a finalidade de estabelecer significados mais claros. É preciso lembrar que a pesquisa é também princípio educativo, que perpassa todo o processo educativo do estudante, e desfazer a ideia de que a pesquisa pertence a uma 
elite profissional. Para isso, no entender de Demo (1997), é fundamental tornar a pesquisa o ambiente didático cotidiano, do professor e do estudante.

Para Chizzotti apud Castanho (2001), a pesquisa pode se transformar num esforço metódico de busca de informações para produzir novos conhecimentos, ampliar a compreensão do mundo e auxiliar na solução dos problemas concretos que as pessoas enfrentam.

Ainda para Chizzotti apud Castanho (2001, p. 106):

O ensino [...] não pode restringir-se à mera transmissão dos conhecimentos já acumulados, e o aprendizado não pode reduzir-se à acumulação das informações. [...] Todo aquele que aprende amplia seu horizonte de saber, põe para si questões novas, pergunta pelo significado do que lhe foi transmitido, reflete e estabelece relações novas entre as observações transmitidas às questões colhidas da sua prática. As dúvidas, curiosidades e necessidades provocam reflexões novas e movem à busca de informações que resolvam os problemas que cada um se pôs.

Estabelecer a pesquisa como princípio educativo num processo de formação inicial de professores da EP, também significa incentivar a capacidade de questionamento crítico do estudante; fazer com que ele consiga identificar as fontes de informação e conhecimento que podem ser utilizadas para levar o processo de pesquisa a bom termo (bibliotecas, acervos culturais, museus, internet); aguçar a capacidade de selecionar e manusear informações; incentivar o uso da tecnologia disponível; possibilitar uma postura científica para o tratamento metodológico das questões.

Nesse processo, Cunha (1996, p 123) alerta que é necessário não perder de vista as lógicas diferentes que regem o ensino e a pesquisa. Segundo ela, “[...] um dos pontos básicos para se enfrentar esta tarefa é mergulhar na reflexão sobre o conhecimento, quando apresenta sua dupla dimensão de processo e produto" e denuncia que a prática escolar tem sido espaço, por excelência do conhecimento como produto. 


\section{Repercussões do TCC na formação de professores da EP}

Para muitos estudantes, o TCC é a primeira e única produção científica construída ao longo dos anos na experiência da graduação. $\mathrm{Na}$ LICA do IFRS - Campus Sertão, assim como nas demais instituições de ensino superior, trata-se de uma construção que segue um rigor epistemológico, estrutural e metodológico, pautados por normas de trabalho acadêmico. "São ensaios teóricos ou pesquisas, geralmente discursivos e conclusivos, que organizam informações de acordo com uma temática definida" (SUAIA apud OLIVEIRA, 2003, p. 58).

$\mathrm{Na}$ formação inicial de professores, a realização do TCC assume papel didático, pois, ao mesmo tempo em que o futuro professor compreende a abrangência da docência desenvolve habilidades e capacidades para a realização de investigação em educação. Não tem por finalidade somente o desenvolvimento de professores pesquisadores, pode direcionar-se para a realização de trabalhos com a participação conjunta de estudantes, professores da educação básica e dos pesquisadores para a construção de referenciais, refinamento de metodologias de pesquisa e de ensino, compartilhamento de problemas e busca de alternativas de encaminhamentos, entre outros.

André (2004) ao debruçar o olhar sobre as repercussões da pesquisa na formação de professores deixa claro que esta é uma discussão complexa e por tal razão a obra registra diferentes posições sobre esse tema e fornece um rico referencial que pode servir para aprofundamento deste estudo, pois propicia pontes para percorrer os intrincados caminhos da pesquisa, sejam eles: a reflexão x pesquisa, a atuação do professor, a pesquisa como um conceito não consensual, as condições para a sua prática, a integração, necessidade e possibilidade da pesquisa no âmbito do trabalho do professor da escola básica (LÜDKE, 2004); a explicitação dos pontos de vistas favoráveis ou contrário às questões sobre se deve ou não usar a expressão professor pesquisador/reflexivo, de que professor e/ou pesquisa se fala quando se usa a expressão professor/pesquisador, que condições têm o 
professor que atua nas escolas, para fazer pesquisas, que pesquisas vêm sendo produzidas pelos professores nas escolas?

Essas são propostas do texto de André (2004, p.55-56) junto com a análise de como "[...] essas ideias vêm sendo traduzidas tanto nos cursos ou programas de formação docente quanto na literatura acadêmica e nos textos oficiais". Um aspecto importante deste trabalho de André (2004) e também apontado por Santos (2004) é assumir a articulação do ensino e pesquisa em vários sentidos, mas também assumir suas diferenças, ter clara a distinção entre um ato pedagógico e um ato de pesquisa, entre uma atividade de ensino e de pesquisa. "Ensino e pesquisa são atividades que exigem conhecimentos, habilidades e atitudes diferentes [...] as tarefas delas decorrentes também têm graus de exigência e implicações diferentes" (ANDRÉ, 2004, p. 56).

Assim, tanto no ensino como na pesquisa ou no ensino com pesquisa há necessidade de atualização constante do professor, por considerar mais os aspectos qualitativos que os aspectos quantitativos. Requer mudança de postura tanto do professor, como do estudante. Ao professor cabe a mudança do papel de transmissor de informações para o de mediador pedagógico junto aos estudantes; a mudança do professor que ensina para o professor que está com o estudante, desenvolvendo um trabalho em equipe onde professor e estudantes são os agentes/parceiros e co-responsáveis nas ações de aprendizagem. Ao estudante cabe se transformar em protagonista no processo de aprendizagem, isto é, se responsabilizar pela busca das informações, aprender a localizá-las, analisá-las, relacionar as novas informações com seus conhecimentos anteriores, dando-lhes significado próprio, emitir conclusões, observar situações de campo e registrá-las, trabalhar com esses dados e procurar chegar à solução de problemas, entre outras atividades (MASETTO, 2001)

Examinando nossa trajetória como professores de um curso de formação inicial de professores da EP, podemos confirmar que o desenvolvimento do TCC é um processo que favorece a participação dos futuros professores em pesquisas, realizando o confronto de dúvidas e 
incertezas com a apropriação dos conceitos. Ao desenvolver um projeto de pesquisa, o estudante desenvolve habilidades investigativas como planejamento, organização, classificação e seleção de dados, análise e interpretação e sintese, além de atitudes como curiosidade, vontade de encontrar explicações, constatação de que as necessidades são de natureza complexa.

No entanto, é importante lembrar que dificilmente o estudante incluirá a investigação em seu processo de aprendizagem se o professor também não o fizer, isto é, se o professor não aprender também a se atualizar e/ou renovar seus conhecimentos por meio de pesquisas, de leituras, de reflexões pessoais, de participação em eventos científicos, etc..

Para assegurar o envolvimento de professores e estudantes nesse princípio educativo orientado pela pesquisa, é preciso disponibilizar algumas condições básicas, especialmente quando se trata de um processo de formação inicial de professores da EP. Uma delas é que a pesquisa deve se tornar um eixo ou um núcleo do curso, elemento orientador de toda a estrutura curricular. Pode traduzir-se numa organização curricular em que componentes curriculares e atividades sejam planejadas coletivamente, com o objetivo de desenvolver habilidades e atitudes de investigação nos estudantes. Pode ainda traduzir-se como mediação, onde os diversos componentes curriculares de cada curso incentivem os estudantes a desenvolver pesquisas que incluam a análise do cotidiano das instituições e/ou espaços de informação, visando aproximar os futuros profissionais da realidade da área que atuarão.

Há ainda a possibilidade dos professores inserirem em suas aulas, temas e projetos de pesquisa nos programas das disciplinas, dando a seus estudantes oportunidade de discutir os resultados de suas pesquisas, os dados analisados, a metodologia utilizada para que, a partir daí, possam propor e gerar novos temas e problemas. Essa dinâmica permite (re)descobrir a concepção de realidade como totalidade, de aprender o conhecimento em movimento, de perceber que as relações educação- 
sociedade, conteúdo-forma, teoria-prática não ocorrem de forma linear, sem conflitos e contradições.

Do conjunto dessas reflexões, é possivel depreender que o processo de desenvolvimento do TCC na formação inicial de professores de EP favorece a melhoria da formação docente. A elaboração e a execução de um projeto de pesquisa pelos estudantes e professores contribui significativamente para a profissionalização de ambos. O movimento da realização do TCC coloca novas perspectivas no campo da formação de professores de EP em que investigar, questionar e confrontar, amplia a compreensão da prática ao mesmo tempo em que propicia o desenvolvimento de capacidades investigativas e reflexivas.

O TCC permite compreender criticamente a prática. Para isso é necessário tomar a análise da prática como ponto de partida para a elaboração da teoria. Isso quer dizer que a investigação não é realizada para experimentar algum modelo teórico na prática, nem verificar os "erros" dos professores frente a algum modelo teórico. A investigação da prática, nesta perspectiva, significa ir a prática e examinar o que está acontecendo e porque está acontecendo. Trata-se de uma análise densa na busca de explicitar quais são os determinantes dos problemas que acontecem na prática. Nesse caso, a teoria tem uma importante contribuição por fornecer indicativos e referenciais que auxiliem no processo de análise da prática. Nesse movimento, a teoria transforma-se ao explicitar a prática.

Como sintese dos indicadores que apontam repercussões do TCC na formação inicial de professores de EP, podemos destacar que o processo de pesquisa desenvolvido neste aspecto do processo formativo dos estudantes não tem por finalidade somente formação de professores pesquisadores, ou seja, para a construção de referenciais, refinamento de metodologias de pesquisa e de ensino, compartilhamento de problemas e possibilidades de superação. O processo de produção do TCC quando abrange a prática profissional do professor, ou seja, o trabalho do professor e o processo didático, pode se tornar em importante instrumento da articulação entre aprendizagem e pesquisa como metodologia para a formação de professores. 


\section{E para concluir... Algumas considerações}

O caminho percorrido na produção deste ensaio, onde buscamos compreender as repercussões do TCC no processo de formação inicial de professores da EP, mostrou que com o desenvolvimento do TCC há possibilidades para novas posturas educacionais e espaço para a construção de propostas alternativas de ensino na formação inicial de professores.

Chegando-se a uma tentativa de finalização, é importante ressaltar inicialmente que o processo de desenvolvimento do TCC não é apenas o novo, é a busca do conhecimento a cada dia, vivido e estimulado em cada linha, cada traço, gesto, imagem, som ou pensamento. Para tanto deve estar inserido no processo de formação inicial de professores da EP, que inclui a instituição formadora, os professores e os estudantes. A questão primordial é tornar a pesquisa o ambiente didático cotidiano, no professor e no estudante, desde logo para desfazer a expectativa arcaica de que pesquisa é coisa especial, de gente especial (DEMO, 1997). Tudo isso para que se crie o hábito da curiosidade, vista como propulsora da pesquisa, da indagação, da busca pelo saber.

As experiências vivenciadas por um curso de licenciatura do IFRS Campus Sertão se caracterizam como trabalho intencional que vem se construindo dialeticamente ao longo dos últimos anos. A instituição formadora, estudantes e professores estão produzindo de maneira singular um conhecimento sobre ensinar, pesquisar e aprender, que ocorre durante as aulas, por meio do desenvolvimento do TCC.

Nas análises realizadas neste ensaio assim como nas interlocuções que foram estabelecidas com alguns pesquisadores da área, por meio da literatura acadêmica, observamos a importância de identificar na produção/vivência de alguns sentidos, destacando-se como experiência de ensino com pesquisa, considerada oportunidade para desenvolver saberes fundamentais e necessários à formação de professores da EP como professor pesquisador. 
Como destaca Freire (1998), a construção ou a produção do conhecimento do objeto implica o exercício da curiosidade, sua capacidade crítica de tomar distância do objeto, de observá-lo, de delimitá-lo, de cindi-lo, de "cercar" o objeto ou fazer sua aproximação metódica, sua capacidade de comparar, de perguntar.

Apesar das possibilidades de avanços com a presença da pesquisa na formação inicial de professores da EP por meio do TCC, é necessário considerar que esse processo depara-se com inúmeras dificuldades e contradições. A principal parece ser que, juntos, estudantes e professor devem se tornar co-autores, parceiros na busca, tanto do conhecimento já existente, quanto daquele em que nem o estudante, nem o professor conhecem ainda. Trata-se de uma caminhada conjunta, entre estudantes, professores e meio, para a assimilação, transmissão e descoberta do conhecimento, e não meros locutor e ouvinte, num sistema de cópia e recópia. (DEMO, 1997).

Nesse trajeto tivemos a oportunidade de observar as repercussões do TCC no processo de formação inicial de professores da EP, com destaque para a constatação de que o sucedimento deste processo depende basicamente dos estudantes e professor que deverão estar aberto para a atividade de pesquisa, a qual envolve o estudo aprofundado de um determinado tema e problema, a relação dos conhecimentos teóricos com a realidade sociocultural, o confronto de ideias entre os profissionais participantes do projeto, a possibilidade do professor em formação ampliar suas concepções acerca dos processos de ensinar e de aprender, além de propiciar que se compreenda a instituição de ensino, ultrapassando as paredes de uma sala de aula.

A caminhada não é simples, pois trata de formas de construção de conhecimentos, o que abrange uma gama enorme de possibilidades. Tomando os apontamentos enunciados neste artigo e as ideias de Balzan (2000) e Tardif (2000), algumas indagações ainda perduram: é possivel a realização de uma formação inicial de professores da EP de boa qualidade sem pesquisa? O professor - especialmente aquele que atua na formação 
inicial de professores da EP - deve ser obrigatoriamente, um pesquisador? A pesquisa pode atrapalhar o ensino? Que condições objetivas e subjetivas são necessárias para estudantes e professores desenvolverem pesquisas? Que relações precisam ser asseguradas entre a instituição de ensino superior formadora e as instituições de educação básica, enquanto nascedouro das pesquisas em educação? Que concepções de pesquisa (e ensino) possuem os professores que orientam trabalhos de pesquisas nos cursos de formação de professores da EP? Quais são os saberes profissionais dos professores de EP, isto é, quais são os saberes (conhecimentos, competências, habilidades etc.) que eles utilizam efetivamente em seu trabalho diário para desempenhar suas tarefas que envolvem ensino e pesquisa? Que relações devem existir entre os saberes profissionais e os conhecimentos acadêmicos, e entre os professores da EP e os professores formadores de professores (pesquisadores ou formadores), no que diz respeito à profissionalização do ensino e à formação de professores da EP?

Essas indagações, acompanhadas dos apontamentos mostrados neste ensaio, sugerem outras buscas teóricas e novas análises de novos dados de processos de desenvolvimento de pesquisa na formação inicial de professores da EP. Essas considerações aqui situadas são recentes e necessitam ser aprofundadas e melhor validadas em outros trabalhos de pesquisa. Trata-se de um tema fecundo para novas investigações, não só para recriar o processo de formação de professores como também para possibilitar a formação de profissionais (professores) autônomos, participativos e críticos, capacitados a refletir e produzir novos conhecimentos, tendo como ponto de partida e de chegada da apreensão a realidade.

\section{REFERÊNCIAS}

ANDRÉ, M.. O papel da pesquisa na formação e na prática dos professores. 3. ed. São Paulo: Papirus, 2004.

BALZAN, N. C. Indissociabilidade ensino-pesquisa como princípio metodológico. In: VEIGA, I. P. A; CASTANHO, M. E. L. M. (orgs.). Pedagogia universitária: a aula universitária em foco. Campinas(SP): Papirus, 2000. p. 
$115-136$.

BRASIL. Resolução $\mathrm{n}^{\circ} 2$, de $1^{\circ}$ de julho de 2015. Brasília, 2015. Disponível em:. Acesso em: http://portal.mec.gov.br/docman/agosto-2017-pdf/70431res-cne-cp-002-03072015-pdf/file. Acesso em: 24 set. 2018.

, Lei n. 9.394, de 20 de dezembro de 1996. Estabelece as diretrizes e bases da educação nacional. Diário Oficial da União, Brasília, DF, 23 dez. 1996. Disponivel em:

http://portal.mec.gov.br/seed/arquivos/pdf/tvescola/leis/lein9394.pdf . Acesso em: 24 set. 2018.

CHIZZOTTI, A. Metodologia do ensino superior: o ensino com pesquisa. In: CASTANHO, S.; CASTANHO, M. E. L. M (orgs.). Temas e textos em metodologia do ensino superior. Campinas(SP): Papirus, 2001. p. 103-112

CUNHA, M. I. Relação ensino e pesquisa. In: VEIGA, I. P. A. (org.). Didática: o ensino e suas relações. Campinas(SP): Papirus, 1996. p. 115-126

DEMO, P. Educar pela pesquisa. Campinas(SP): Autores Associados, 1997.

FREIRE, P. Pedagogia da Autonomia: saberes necessários à prática educativa. 9. ed. Rio de Janeiro: Paz e Terra, 1998.

GATTI, B. A. Pesquisar em educação: considerações sobre alguns pontoschave. Revista Diálogo Educacional. Curitiba(PR), n. 19, p. 25-35, set./dez. 2006

LÜDKE, M.; CRUZ, G. B. Aproximando universidade e escola de educação básica pela pesquisa. Cadernos de Pesquisa, São Paulo, v. 35, n. 125, p. 81109, maio/ago. 2005.

LÜDKE, M. A complexa relação entre o professor e a pesquisa. In: ANDRÉ, M. (org.). O papel da pesquisa na formação e na prática dos professores. 3. ed. Campinas, SP: Papirus, 2004, p.27-54.

LÜDKE, M. et al.. O que conta como pesquisa? São Paulo: Cortez, 2009.

MASETTO, M. T. Atividades pedagógicas no cotidiano da sala de aula universitária: reflexões e sugestões práticas. In: CASTANHO, S.; CASTANHO, M. E. L. M. (orgs.). Temas e textos em metodologia do ensino superior. Campinas(SP): Papirus, 2001. p. 83-102.

MASSI, L.; QUEIROZ, S. L. Iniciação científica: aspectos históricos, organizacionais e formativos da atividade no ensino superior brasileiro. São Paulo: Editora Unesp Digital, 2015. Disponivel em: http://books.scielo.org/id/s3ny4/pdf/massi-9788568334577.pdf. Acesso em: 07 maio 2018.

MORAES, R.; RAMOS, M.; GALIAZZI, M. C. Pesquisa em sala de aula: 
fundamentos e pressupostos. 2002.

OLIVEIRA, G. A. P. A concepção de egressos de um curso de Pedagogia acerca da contribuição do trabalho de conclusão de curso. $2003.136 \mathrm{f}$. Dissertação de Mestrado. Faculdade de Educação, Universidade Estadual de Campinas, Campinas, São Paulo, 2003.

SANTOS, L. L. C. P. Dilemas e perspectivas na relação entre ensino e pesquisa. In: ANDRE, M. (org. ). O papel da pesquisa na formação e na prática dos professores. 3. ed. Campinas, SP: Papirus, 2004. p.11-25.

TARDIF, M. Saberes profissionais dos professores e conhecimentos universitários Elementos para uma epistemologia da prática profissional dos professores e suas consequências em relação à formação para o magistério. In: Revista Brasileira de Educação. Rio de Janeiro, n. 13, p. 5-13, jan./fev./mar./abr. 2000. 